\title{
IMPLEMENTASI KLASIFIKASI BAYESIAN UNTUK STRATEGI MENYERANG JARAK DEKAT PADA NPC (NON PLAYER CHARACTER)MENGGUNAKAN UNITY 3D
}

\author{
Siti Asmiatun, M.Kom ${ }^{1}$ \\ Fakultas Teknologi Informasi dan Komunikasi \\ Universitas Semarang
}

\author{
Aria Hendrawan, M.Kom ${ }^{2}$ \\ Fakultas Teknologi Informasi dan Komunikasi \\ Universitas Semarang
}

\begin{abstract}
In a game against the enemy attack strategy should be applied, making it more appealing game players to finish the game up with the objectives to beachieved. This study discusses the strategy of attacking at close range to the NPC (Non Player Character ). In a game, especially for FPS ( First Person Shooter), we need a strategy $N P C$, with the aim to make the game more attractive and realistic. Strike strategy in this research is to divide some of the behavior of NPCs attack when in the position closest to the enemy. This research applies Bayesian algorithm for classifying the behavior of the NPC attack. The classification is expected to improve the strategy against an enemy attack. NPC assault classification is divided into two offensive behavior is the behavior of hitting and biting behavior. As for the variables used in Bayesian classification is health points, attack points player and a distance obtained from NPC conditions. From the test results using testing method of Bayesian classification confusion matrix, with trial games 10 times, has resulted in the presentation level of accuracy in the confusion matrix reach a percentage of $80 \%$. This proves that the behavior classification melee attack with Bayesian classification method can be applied with good resultsDalam sebuah game strategi penyerangan untuk melawan musuh harus diterapkan, sehingga lebih menarik pemain game untuk menyelesaikan permainan sampai dengan tujuan yang akan dicapai. Penelitian ini membahas tentang strategi menyerang jarak dekat untuk NPC (Non Player Character).
\end{abstract}

Keywords-game; clasification; naive; bayes; strategi; menyerang; fps

\section{PENDAHULUAN}

Artifical Intelligence (AI) pada game FPS umumnya terdiri dari perencanaan path, mengambil item, menggunkan item, dan berperang [1]. Khusus untuk berperang NPC diharapkan mempunyai strategi-strategi khusus seperti halnya manusia [2][5]. Strategi yang dimaksud bisa berupa strategi mengejar lawan, menyerang lawan maupun menghindari lawan.
Model strategi menyerang bisa bermacammacam, misalnya strategi menyerang dengan memancing serangan musuh, kemudian pada kondisi tertentu perilaku berubah menjadi menghindar. Jika NPC bergerak menghindar ke arah tim, maka NPC akan mendapatkan bantuan serangan dari rekan satu tim. Bagaimanapun model strategi menyerang, umumnya mempunyai tujuan akhir mengalahkan musuh [3]. Model strategi menyerang dalam sebuah game harus direncananakan untuk membuat game yang tidak membosankan bagi pemain.

Banyak penelitian yang membahas tentang strategi penyerangan salah satunya penelitian dari Yunifa dkk tentang strategi menyerang menggunakan logika fuzzy telah menghasilkan tingkat kemenangan hingga $80 \%$ ketika diujicobakan dengan musuh yang mempunyai perilaku umum yaitu menyerang dan menghindari tembakan [6]. Penelitian strategi menyerang juga dilakukan rianto dan norman menggunakan optimasi dengan Simmulated Annealing telah menghasilkan kinerja strategi menyerang yang lebih baik dari segi waktu proses [4].

Meninjau penelitian dari siti asmiatun dkk tentang strategi menyerang jarak dekat menggunnakan klasifikasi bayesian [9], terdapat beberapa kekurangan salah satunya belum diimplementasikan ke dalam tools game. Dari beberapa penelitian tersebut, penelitian ini difokuskan untuk implementasi startegi menyerang menggunakan klasifikasi dengan algoritma naive bayes menggunakan tools game engine unity. Maka dari itu, dengan pengembangan penelitian ini diharapkan nanti dapat menghasilkan sebuah game yang menarik dengan akurasi yang lebih baik lagi dari penelitian sebelumnya.

\section{LANDASAN TEORI}

\section{A. Game}

Game berasal dari kata bahasa inggris yang memiliki arti dasar Permainan. Permainan dalam hal ini merujuk pada pengertian "kelincahan intelektual" (intellectual playability). Game juga bisa diartikan sebagai arena keputusan dan aksi pemainnya. Ada target-target yang ingin dicapai 
pemainnya. Kelincahan intelektual, pada tingkat tertentu, merupakan ukuran sejauh mana game itu menarik untuk dimainkan secara maksimal.

Mengacu pada Adams (2010) game harus menghibur pemain, yaitu:

1. Game harus menghadirkan imajinatif, pengalaman koheren, sehingga desainer harus memiliki visi.

2. Game harus menjual dengan baik, sehingga desainer harus mempertimbangkan selera konsumen.

3. Game dengan lisensi harus bayar kembali biaya lisensi, sehingga desainer harus mengerti keuntungan lisensi dan memanfaatkannya sebagai keunggulan.

Game harus menawarkan tantangan kecerdasan dan pengalaman yang mulus, sehingga desainer harus mengerti teknologi.[7]

\section{B. NPC (Non Player Character)}

Autonomous character adalah jenis otonomous agent yang ditujukan untuk penggunaan komputer animasi dan media interaktif seperti games dan virtual reality. Agen ini mewakili tokoh dalam cerita atau permainan dan memiliki kemampuan untuk improvisasi tindakan mereka. Ini adalah kebalikan dari seorang tokoh dalam sebuah film animasi, yang tindakannya ditulis di muka, dan untuk "avatar" dalam sebuah permainan atau virtual reality, tindakan yang diarahkan secara real time oleh pemain. Dalam permainan, karakter otonom biasanya disebut NPC (Non-Player Character) [3].

\section{Naive Bayesian Classification}

Nä̈ve Bayes merupakan pengklasifikasian dengan metode probabilitas dan statistik yang dikemukakan oleh ilmuwan Inggris Thomas Bayes, yaitu memprediksi peluang di masa depan berdasarkan pengalaman di masa sebelumnya sehingga dikenal sebagai Teorema Bayes. Menurut Olson dan Delen (2008:102) menjelaskan Nä̈ve bayes untuk setiap kelas keputusan, menghitung probabilitas dengan syarat bahwa kelas keputusan adalah benar, mengingat vektor informasi obyek. Algoritma ini mengasumsikan bahwa atribut obyek adalah independen. Probabilitas yang terlibat dalam memproduksi perkiraan akhir dihitung sebagai jumlah frekuensi dari "master" tabel keputusan [8].

\section{METODE PENELITIAN}

Metode penelitian yang digunakan untuk penelitian ini adalah dengan menggunakan pendekatan metode Bayesian. Seperti yang diilustrasikan dalam roadmap dibawah ini menjelaskan tentang tahap - tahap yang akan dilakukan dalam penelitian ini.

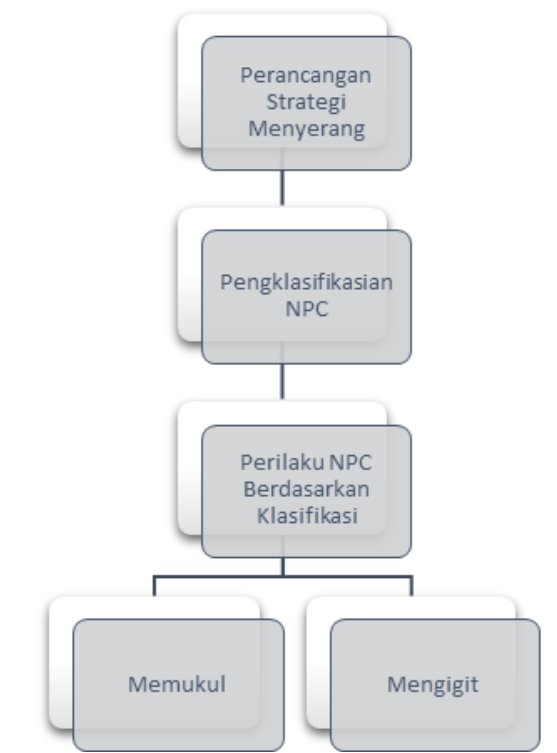

Gambar 3.1 Roadmap Penelitian

\section{A. Concept}

DefinePada tahapan ini dilakukan analisis dari beberapa NPC untuk mendapatkan data yang menjadi variabel atau dataset dalam perhitungan bayesian. Tahapan ini terdiri dari :

1. Perancangan Strategi Menyerang

Dalam menentukan strategi penyerangan diperlukan beberapa perancangan untuk persiapan sebelum menentukan strategi penyerangan. Penelitian ini akan menggunakan beberapa perilaku untuk strategi penyerangan yaitu perilaku Memukul dan Mengigit. Sedangkan parameter yang digunakan untuk menentukan perilaku adalah jarak, Health Point (HP) dan Attack Power player (APP) dari NPC, parameter dikelompokkan menjadi tiga kategori sebagai berikut:

Tabel 3.1 Kategori APP

\begin{tabular}{|l|l|}
\hline APP $<5500$ & Lemah \\
\hline APP $>5500$ & Kuat \\
\hline
\end{tabular}

Tabel 3.2 Kategori HP

\begin{tabular}{|l|l|}
\hline HP $<55000$ & Besar \\
\hline HP $>55000$ & Kecil \\
\hline
\end{tabular}

Tabel 3.3 Kategori Jarak

\begin{tabular}{|c|c|}
\hline Jarak $>3.0$ & Jauh \\
\hline Jarak $<1.5$ & Dekat \\
\hline
\end{tabular}


Tabel 3.4 Rule penentuan perilaku

\begin{tabular}{|l|}
\hline Jika APP kuat dan jarak jauh dan HP jauh maka memukul \\
\hline Jika APP kuat dan jarak jauh dan HP sedang maka memukul \\
\hline Jika APP kuat dan jarak dekat dan HP dekat maka menggigit \\
\hline Jika APP kuat dan jarak dekat dan HP jauh maka menggigit \\
\hline Jika APP lemah dan jarak jauh dan HP sedang maka memukul \\
\hline Jika APP lemah dan jarak jauh dan HP dekat maka memukul \\
\hline Jika APP lemah dan jarak dekat dan HP jauh maka mengigit \\
\hline $\begin{array}{l}\text { Jika APP lemah dan jarak dekat dan HP sedang maka } \\
\text { menggigit }\end{array}$ \\
\hline
\end{tabular}

2. Klasifikasi NPC (Non Player Character)

Dalam perhitungan algoritma Bayesian,terlebih dahulu menentukan jenis atribut yang akan dipakai untuk perhitungan Bayesian. Dalam kasus klasifikasi NPC, atribut yang digunakan adalah Jarak, Health Point (HP) dan Attack Power Player (APP) yang ada pada masing - masing NPC.

Tabel 3.5 Sambel atribut NPC 1

\begin{tabular}{|r|r|c|c|}
\hline $\begin{array}{c}\text { Attack Power } \\
\text { Player (DPP) }\end{array}$ & $\begin{array}{c}\text { Jarak } \\
\text { NPC }\end{array}$ & $\begin{array}{c}\text { Health } \\
\text { Point } \\
\text { (HP) }\end{array}$ & Perilaku \\
\hline kuat & jauh & Besar & memukul \\
\hline kuat & dekat & Besar & mengigit \\
\hline kuat & jauh & Kecil & memukul \\
\hline lemah & jauh & Besar & $\begin{array}{c}\text { Memuku } \\
\text { l }\end{array}$ \\
\hline kuat & dekat & Besar & $\begin{array}{c}\text { Menggig } \\
\text { it }\end{array}$ \\
\hline kuat & dekat & Kecil & $\begin{array}{c}\text { menggigi } \\
\text { t }\end{array}$ \\
\hline lemah & jauh & Besar & $?$ \\
\hline
\end{tabular}

Dari dataset diatas, dapat dihitung dengan menggunakan teorema Bayes sebagai berikut :

$$
P\left(C_{i} \mid \boldsymbol{X}\right)=\frac{P\left(\boldsymbol{X} \mid C_{i}\right) P\left(C_{i}\right)}{P(\boldsymbol{X})} .
$$

Keterangan :

$\mathrm{P}\left(\mathrm{C}_{\mathrm{i}} \mid \mathrm{X}\right)=$ Probabilitas hipotesis $\mathrm{C}_{\mathrm{i}}$ jika diberikan fakta atau record $\mathrm{X}$ (Posterior probability) $\mathrm{P}\left(\mathrm{X} \mid \mathrm{C}_{\mathrm{i}}\right)=$ mencari nilai parameter yang memberi kemungkinan yang paling besar (likelihood) $\mathrm{P}\left(\mathrm{C}_{\mathrm{i}}\right)=$ Prior probability dari $\mathrm{X}$ (Prior probability) $\mathrm{P}(\mathrm{X})=$ Jumlah probability tuple yg muncul Jadi perhitungan yang dihasilkan dari teorema bayes diatas adalah:
Asumsi :

$\mathrm{Y}=$ Perilaku

$\mathrm{X} 1=\mathrm{APP}$

$\mathrm{X} 2=\mathrm{Jarak}$

$\mathrm{X} 3=\mathrm{HP}$

Dengan metode bayes dapat dihitung :

$\mathrm{P}(\mathrm{X} 1=$ Lemah, $\mathrm{X} 2$ = Jauh, X3 = Besar $\mid$ Memukul $)$

$=$

$\{1 / 3 \cdot 3 / 3 \cdot 2 / 3\} \cdot 3 / 6=1$

$\mathrm{P}(\mathrm{X} 1=$ Lemah, $\mathrm{X} 2=$ Jauh, $\mathrm{X} 3=$ Kuat $\mid$ Mengigit $)=$ $\{0 / 3.0 / 1 \cdot 2 / 1\} .3 / 6=0$

Sehingga menghasilkan table setiap perilaku sebagai berikut :

Tabel 3.6 Hasil Naïve Bayes Per perilaku

\begin{tabular}{|l|l|}
\hline \multicolumn{1}{|c|}{ Perilaku } & Hasil \\
\hline Memukul & 1 \\
\hline Menggigit & 0 \\
\hline
\end{tabular}

3. Penentuan Perilaku NPC (Non Player Character) Berdasarkan dari tabel 3.6 nilai probabilitas yang paling tinggi dimiliki oleh kategori Memukul. Jadi perilaku yang akan digunakan NPC adalah perilaku Memukul.

\section{HASIL DAN PEMBAHASAN}

Hasil implementasi yang dibahas dalam bab ini dideskripsikan melalui gambar tampilan print screen pada halaman tertentu sesuai dengan langkahlangkah pengembangan metode penelitian yang digunakan yaitu meliputi :

A. Pengumpulan Kebutuhan Game

1) Perancangan Finite State Machine (FSM)

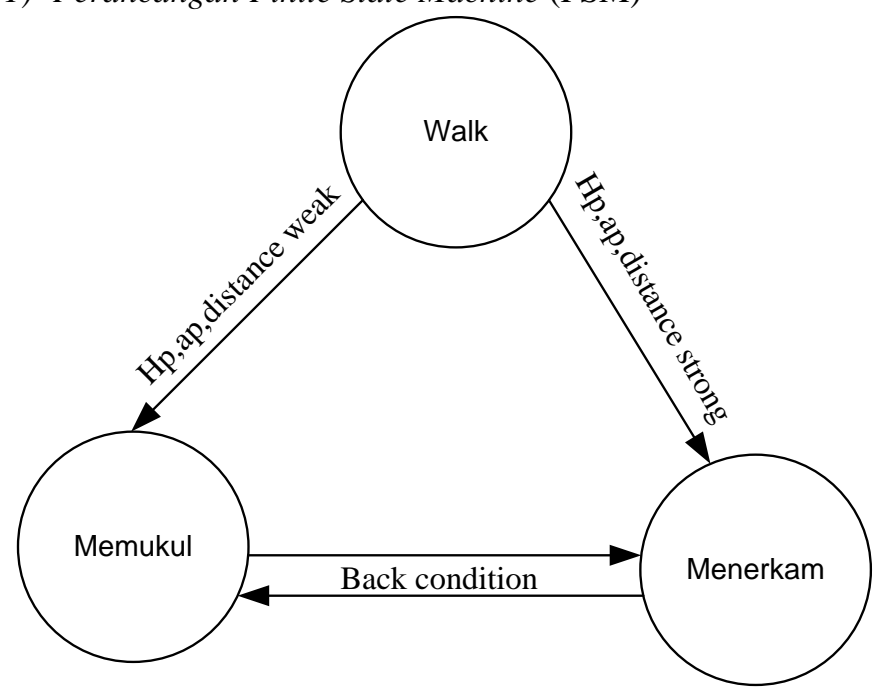


Gambar 4.1 Finite State Machine penyerangan

2) Analisa Tingkat Kesulitan

Tingkat kesulitan akan berbeda di setiap levelnya dilihat dari jumlah musuh, kekuatan musuh, dan selang waktu setiap tembakan yang dilakukan musuh. Di bawah ini adalah perbandingan tingkat kesulitan tiap level, dapat dilihat pada tabel 4.1 .

Tabel 4.1 Analisa kesulitan Scoring Non Player Character

\begin{tabular}{|c|c|c|}
\hline Keterangan & Level1 & Level 2 \\
\hline Jumlah Enemy & $\begin{array}{l}12 \text { Zombie, } \\
1 \text { Zombie } \\
\text { Bos }\end{array}$ & $\begin{array}{l}20 \text { Zombie, } 1 \\
\text { Zombie Bos }\end{array}$ \\
\hline $\begin{array}{c}\text { Jumlah } \\
\text { Tembakan }\end{array}$ & 5 Kali & 10 Kali \\
\hline $\begin{array}{c}\text { Strategi } \\
\text { Penyerangan } \\
\text { Enemy }\end{array}$ & \multicolumn{2}{|c|}{ Memukul dan Menerkam Player } \\
\hline Karakter Player & \multicolumn{2}{|c|}{$\begin{array}{c}\text { Berjalan, Melompat, Menembak, } \\
\text { Mengambil Darah, Membuang } \\
\text { Senjata, Mengambil Senjata, } \\
\text { Mengambil Obat. }\end{array}$} \\
\hline
\end{tabular}

B. Pengumpulan Model Game (Material Collecting)

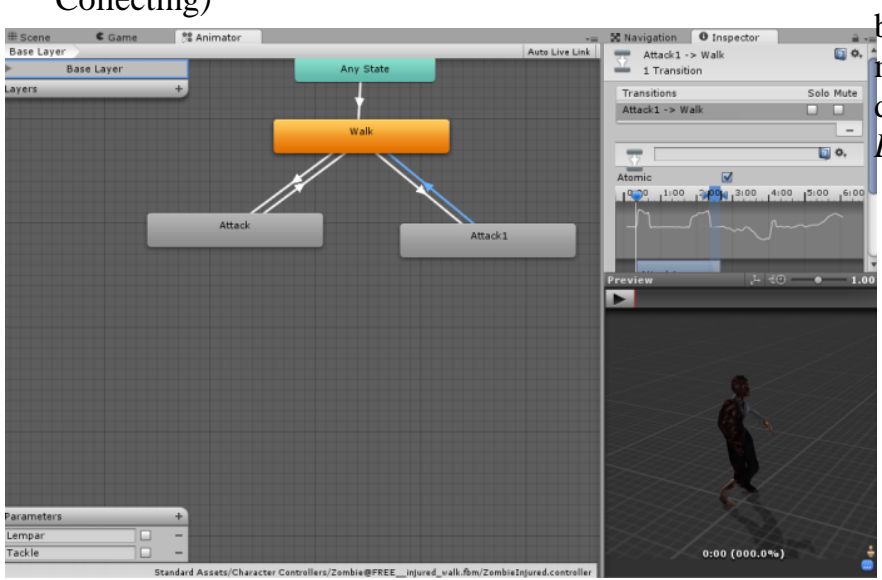

Gambar 4.2 Animator Attack ke Walk

C. Pembuatan Pengembangan Game (Assembly)

Pada tahap ini, ada beberapa data training yang akan di implementasikan dengan formula naive Bayes Classifier.

1) Dataset

Tahapan diawali dengan melakukan pengambilan data sample atau conntoh data dari konidisi zombie. Dimana data tersebut dapat dilihat pada tabel 4.3 .
Tabel 4.2 Data training untuk klasifikasi bayes

\begin{tabular}{|c|c|c|c|}
\hline HP & Jarak & AP & Perilaku \\
\hline kuat & jauh & besar & memukul \\
\hline kuat & dekat & Besar & mengigit \\
\hline kuat & jauh & kecil & memukul \\
\hline lemah & jauh & besar & Memukul \\
\hline kuat & dekat & besar & Menggigit \\
\hline kuat & dekat & kecil & menggigit \\
\hline lemah & jauh & besar & Memukul \\
\hline kuat & jauh & besar & memukul \\
\hline kuat & dekat & Besar & mengigit \\
\hline kuat & jauh & Kecil & memukul \\
\hline kuat & dekat & Besar & mengigit \\
\hline kuat & dekat & Kecil & mengigit \\
\hline
\end{tabular}

2) Modul AI Enemy

Pada tahapan ini game dibuat dengan menggunakan Unity $3 D$ v4.3.4f2. Tahap ini akan dikembangkan modul-modul program untuk program utama serta program untuk masing-masing agent yang akan digunakan dalam game sesuai dengan perilaku zombie berdasarkan naive Bayes Classifier yang menggunakan data training pada tabel 4.5 diatas. Berikut flowchart script modul naive Bayes Classifier: 


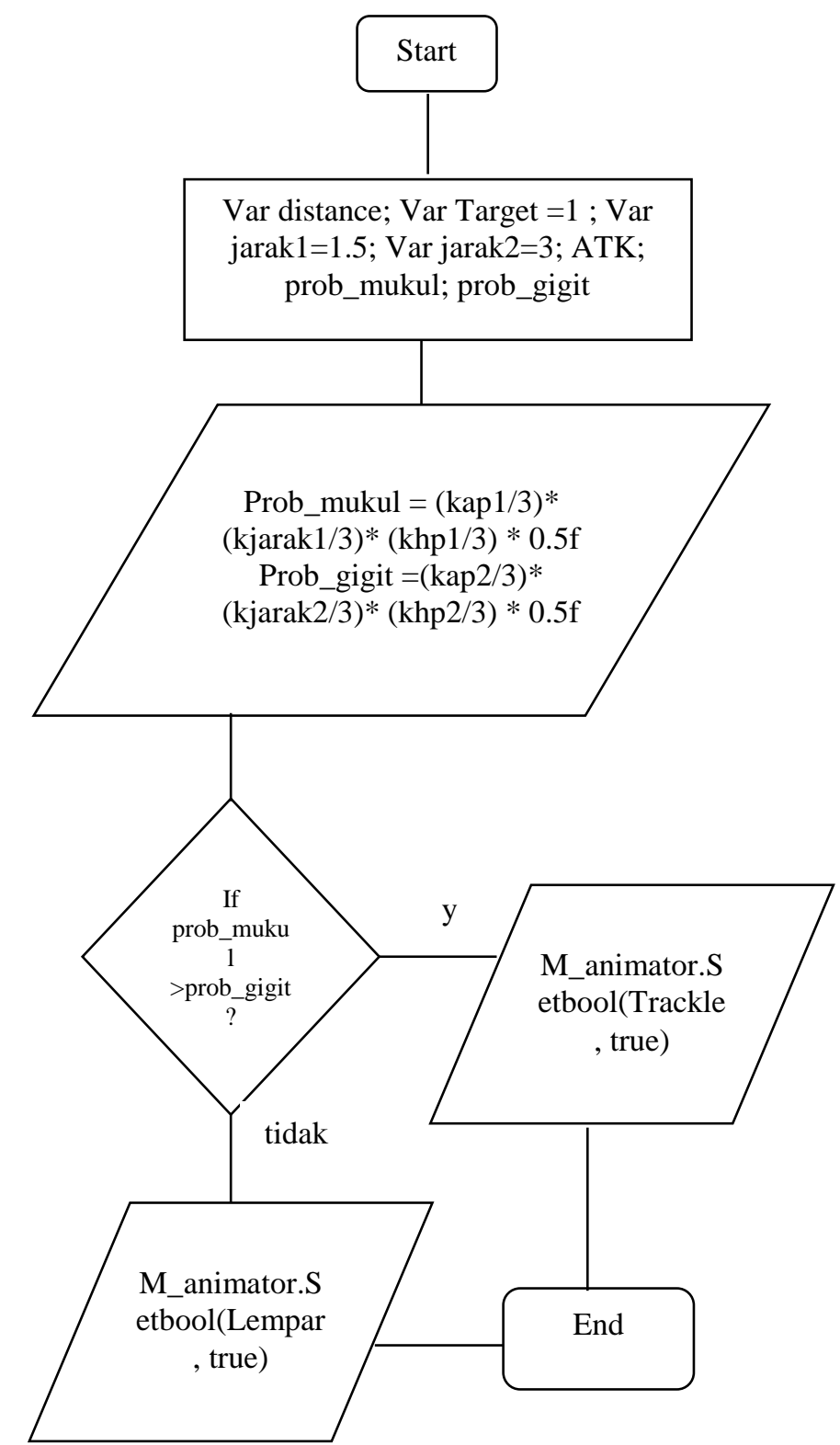

Gambar 4.3 Flowchart kalsifikasi naive bayes

\section{Pengujian Skenario}

Pengujian skenario bertujuan untuk mengetahui hasil perbandingan metode bayesian dengan pohon keputusan melalui interface game. Untuk menentukan kebenaran uji, diperlukan sebuah rule yang menjadi penentuan perilaku. Sebuah rule yang ditentukan oleh developer game tersebut bisa dilihat ditabel 3.1 sampai dengan tabel 3.4 .
Untuk penentuan perilaku pada metode bayesian, dibutuhkan perbandingan nilai probabilistik perilaku satu dengan nilai probabilistik lainnya. Jadi kondisi tersebut bisa dikatakan diterima jika :

Probabillitas mukul > probabilitas gigit $=$ memukul

Probabilitas gigit > probabilitas mukul = menggigit

Sedangkan untuk metode rule-based dapat dikatakan diterima dengan kondisi sebagai berikut :

Nilai $h p>$ nilai ap \&\& jarak $<1.5=$ menggigit

Nilai $h p<$ nilai ap $\& \&$ jarak $>3=$ memukul

\section{E. Pengujian Metode bayesian}

Berdasarkan hasil pengujian skenario, diperoleh hasil bahwa terdapat 8 yang sesuai dengan kelas yang diberikan dan 2 hasil yang tidak sesuai dengan hasil yang diberikan. Berikut ini dijabarkan contoh confusion matrix dari hasil pengujian percobaan skenario dengan metode naive bayes dapat diambil kesimpulan sebagai berikut :

Tabel 4.3 Hasil validasi

\begin{tabular}{|c|c|c|c|}
\hline $\begin{array}{l}\text { Percobaan } \\
\text { ke- }\end{array}$ & $\begin{array}{l}\text { Perilaku } \\
\text { yang } \\
\text { diharapkan }\end{array}$ & $\begin{array}{l}\text { Hasil } \\
\text { perilaku }\end{array}$ & $\begin{array}{l}\text { Kesimpul } \\
\text { an }\end{array}$ \\
\hline 1 & Menggigit & Menggigit & Valid \\
\hline 2 & Memukul & Memukul & Valid \\
\hline 3 & Menggigit & $\begin{array}{l}\text { Menggigit } \\
\text { dan } \\
\text { terbang }\end{array}$ & $\begin{array}{l}\text { Tidak } \\
\text { valid }\end{array}$ \\
\hline 4 & Memukul & Memukul & Valid \\
\hline 5 & Memukul & Memukul & Valid \\
\hline 6 & Menggigit & Menggigit & Valid \\
\hline 7 & Memukul & Memukul & Valid \\
\hline 8 & Menggigit & Menggigit & Valid \\
\hline 9 & Menggigit & $\begin{array}{l}\text { Menggigit } \\
\text { terbang }\end{array}$ & $\begin{array}{l}\text { Tidak } \\
\text { valid }\end{array}$ \\
\hline 10 & Memukul & Memukul & Valid \\
\hline 11 & Menggigit & Menggigit & Valid \\
\hline 12 & Memukul & Memukul & Valid \\
\hline 13 & Menggigit & $\begin{array}{l}\text { Menggigit } \\
\text { dan } \\
\text { terbang }\end{array}$ & $\begin{array}{l}\text { Tidak } \\
\text { valid }\end{array}$ \\
\hline
\end{tabular}




\begin{tabular}{|c|c|c|c|}
\hline 14 & Memukul & Memukul & Valid \\
\hline 15 & Memukul & Memukul & Valid \\
\hline 16 & Menggigit & Menggit & Valid \\
\hline 17 & Menggigit & $\begin{array}{l}\text { Menggigit } \\
\text { dan } \\
\text { terbang }\end{array}$ & $\begin{array}{l}\text { Tidak } \\
\text { valid }\end{array}$ \\
\hline 18 & Menggigit & Menggigit & Valid \\
\hline 19 & Memukul & Memukul & Valid \\
\hline 20 & Memukul & Memukul & Valid \\
\hline
\end{tabular}

Dari tabel diatas, dapat disimpulkan dengan tabel confusion matrix dengan Class a dan Class b pada tabel confusion matrix berturut-turut menunjukkan class memukul dan menggigit yaitu sebagai berikut :

Tabel 2.4 Contoh Confusion matrix

\begin{tabular}{|l|c|c|c|}
\hline \multicolumn{4}{|r|}{ Predicted Class } \\
\hline \multicolumn{4}{|c|}{ Class $a=$ memukul Class $b=$ menggigit } \\
\hline $\begin{array}{l}\text { Actual } \\
\text { Class }\end{array}$ & Class $a$ & 10 & 0 \\
\cline { 2 - 4 } & Class $b$ & 6 & 4 \\
\hline
\end{tabular}

Berdasarkan hasil confusion matrix terlihat bahwa 10 record pada class a diprediksi tepat sebagai class a dan sebanyak 0 record diprediksikan tidak tepat sebagai class $b$. Selanjutnya, seluruh record pada class $b$ terdapat 4 record diprediksi tidak tepat pada class a dan 6 record diprediksi tepat sebagai class $b$.

Dari hasil tersebut dapat dihitung akurasinya sebagai berikut :

$$
80 \% \text { Akurasi } \quad \times 100=
$$

$$
10+0+6+4
$$

Jadi dapat disimpulkan bahwa perhitungan persentase tingkat akurasi pada confusion matrix mencapai nilai persentase sebesar $80 \%$.

\section{F. Distribusi}

Pada tahao distribusi merupakan tahapan yang digunakan untuk membangun game kedalam sebuah aplikasi game yang sesuai dengan perngkat yang dibutuhkan. Untuk membangun game tersebut, langkah pertama yaitu membuka build setting yang terdapat dimenu file. Kemudian setelah muncul pengaturan build, terlebih dahulu kita menambahkan beberapa file scene game yang dibutuhkan melalui tombol add current. Dibagian bawah build settings terdapat pilihan platform yang digunakan untuk memilih perangkat distribusi yang

mendukung game tersebut. Kemudian yang terakhir pilih tombol build dibagian paling bawah.

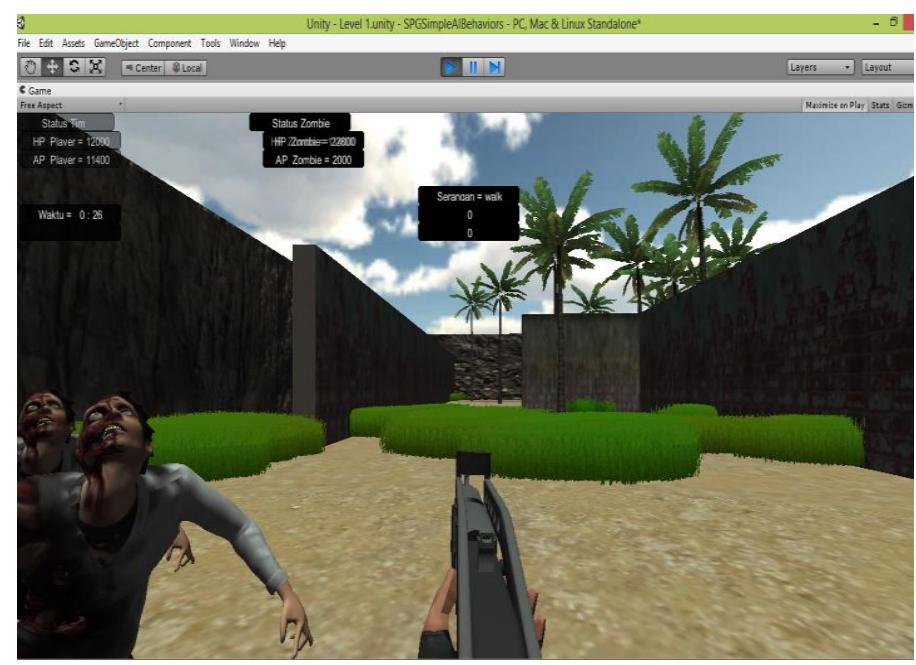

Gambar 4.4 Display game

\section{KESIMPULAN DAN SARAN}

Dari hasil penelitian game yang dibuat dan dikembangkan, maka dapat disimpulkan bahwa berdasarkan hasil testing, ada beberapa pengujian yang digunakan dalam game ini yaitu pengujian interface yang mnguji fungsi-fungsi game secara interface ke pemain berhasil berfungsi dengan baik. Kemudian ada pengujian skenario dari 10 kali percobaan game dapat melakukan skenario yang diujikan menggunakan metode bayesian, sedangkan dengan metode rule-based ada beberapa yang tidak bisa dilakukan. Untuk pengujian metode klasifikasi bayesian menggunakan pengujian confusion matrix. Dari percobaan permainan sebanyak $10 \mathrm{kali}$, telah menghasilkan persentase tingkat akurasi pada confusion matrix mencapai nilai persentase sebesar $80 \%$.

Kedepannya diharapkan klasifikasi perilaku dapat ditambahkan paramater dengan metode lain sehingga ada perbandingan metode. Selain itu dibutuhkan tambahan perlaku menyerang untuk zombie, sehingga permainan yang dihasillkan lebih menarik pemain. Karena kelemahan dipenelitian ini, zombie didalam game tidak dapat menyerang musuh ketika posisi paling dekat dengan musuh karena collider zombie menyentuh collider musuh, sehingga mengakibatkan zombie terbang dan serangan zombie tidak fokus. Hal ini diperlukan penelitian lebih lanjut untuk menentukan jarak antara zombie dengan musuh. 


\section{DAFTAR PUSTAKA}

[1] JinHyuk Hong dan Sung-Bae Cho. "Evolving Reactive NPCs for the Real-Time Simulation Game”. CIG, 2005.

[2] Yunifa Miftachul Arif, Fachrul Kurniawan dan Fresy Nugroho. "Desain Perubahan Perilaku pada NPC Game Menggunakan Logika Fuzzy”. National Seminar on Electrical, Informatics, and Its Education, 2011.

[3] Yunifa Miftachul Arif, Mochamad Hariadi dan Supeno Mardi S.N. "Strategi Menyerang pada Game FPS Menggunakan Hierarchy Finite Machine dan Logika Fuzzy". 2012

[4] Rianto dan Noorman." Optimasi Strategi Menyerang NPC Group Pada Game Pertarungan Jarak Dekat Dengan Menggunakan Simmulated Annealing”. Institud Teknologi Surabaya. 2012

[5] McPartland M,and Gallagher M. "Creating a Multi-Purpose First Person Shooter Bot With
Reinforcement Learning “. IEEE Symposium on Computational Intelligence and Games, pp. 143-150,2008.

[6] Yunifa Miftachul Arif, Moch.Hariadi, Supeno M. "Integrasi Hierarchy Finite State Machine Dan Logika Fuzzy Untuk Desain Strategi NPC Game”. Jurusan Teknik Elektro. Institud Teknologi Surabaya. 2011

[7] Adams, E. (2010). Fundamental of Game Design, 2nd Edition. Pearson Education, Inc, Berkeley.

[8] D.L. Olson and D. Delen.” Advanced data mining

techniques". Springer Verlag. ISBN3540769161. 2008

[9] Siti Asmiatun, Latius Hermawan dan Tri Daryanti. "Strategi Menyerang Jarak Dekat Menggunakan Klasifikasi Bayesian Pada NPC (Non Player Character)". Seminar Nasional Teknologi Informasi dan Komunikasi Terapan. ISBN979-26-0266-6. 2013 